\title{
太阳耀斑出现在 $\mathrm{H}_{\beta}$ Doppler 速度图的 红移区的实测证据 ${ }^{*}$
}

\author{
艾国样 张洪起 李 京 李 威 陈济民 \\ （中国科学院北京天文台，北京 100080）
}

关喓调太阳耀班、色球速度场、红移

1989 年 3 月, 太阳上出现超级太阳活动区, 怀柔编号 89065 , Boulder 编号 5395, 日球坐 标是 N33, L260. 这个区是近十多年来黑子面积最大、活动最激烈的太阳活动区, 发生了连 续的太阳大耀、 $\mathrm{X}$ 射线事件和特大质子事件。北京天文台怀柔太阳观测站从 3 月 7 日至 17 日连续获得高质量的矢量磁图- $\mathrm{H}_{8}$ Doppler 速度图, 并观测到 29 次耀斑. 这些丰富的资

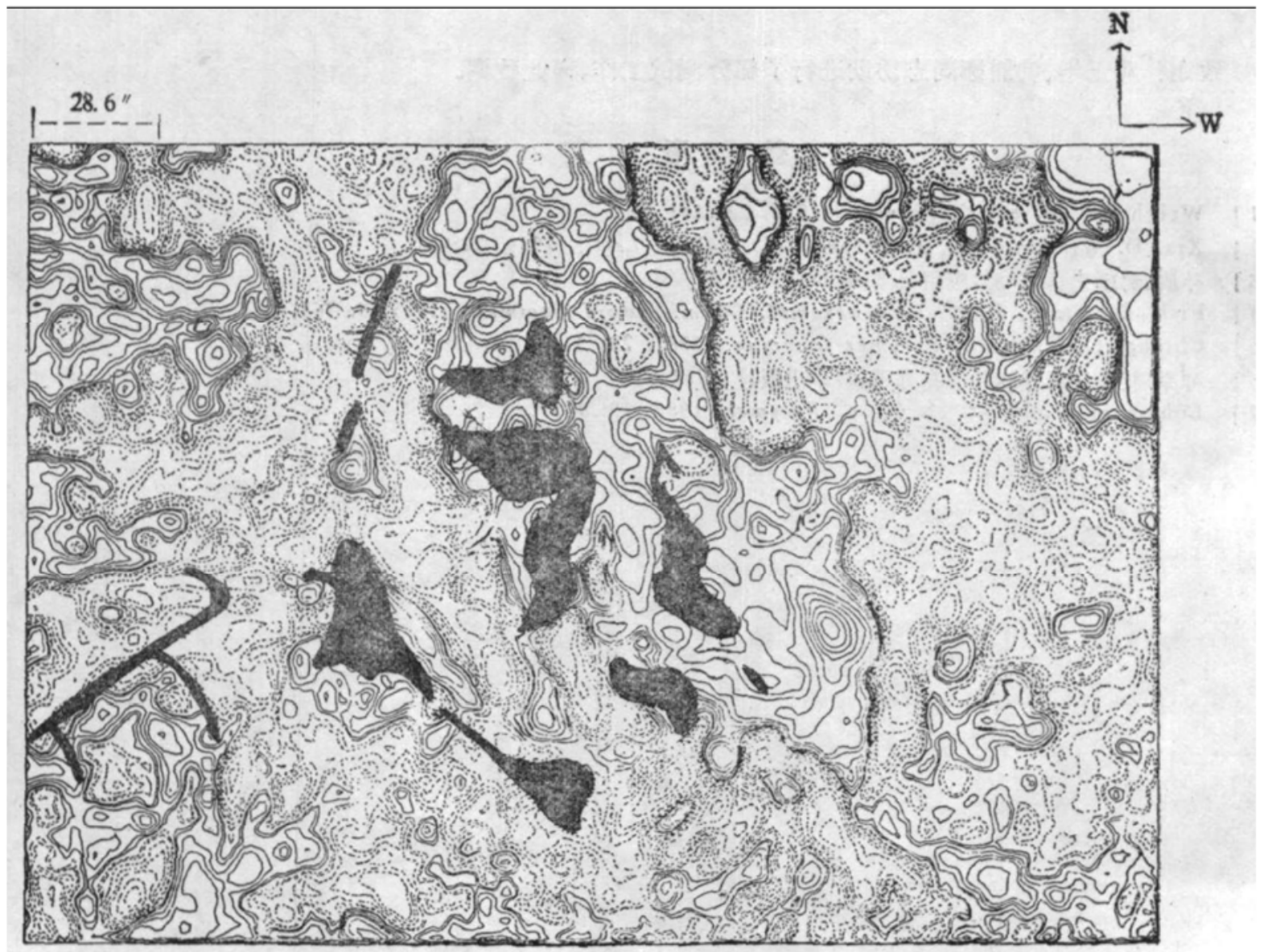

图 1 矢量磁图 0355UT

本文 1989 年10月20日收到。1990年6月9日收到改稀.

*国家自然科学盖金资助项目. 
料除十分清楚地表明磁挤压与磁剪切对耀出出现的重要作用外, 还发现了一个十分重要茾且 具有普遍意义的新现象, 即数出现在 $0.5 \mathrm{~h}$ 至 $2 \mathrm{~h}$ 之前的 $\mathrm{H}_{\beta}$ Doppler 速度场反变线的红 移一侧, 具体特征如下:

（1）耀斑出现在 0.5-2h 之前的 $\mathrm{H}_{\beta}$ Doppler 速度场反变线的红移一侧. 1988 年曾指

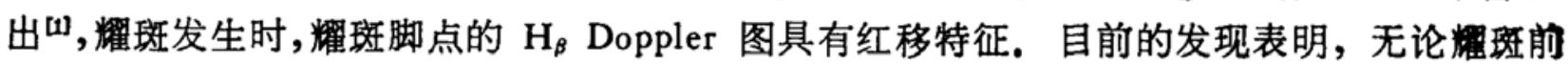
或耀斑时, 色球中耀鉛都具有下降流特征. 在该区观测的 29 个耀斑的 138 个亮点和亮带中, 123 个在耀斑前有 $\mathrm{H}_{\beta}$ Doppler 图, 其中 119 个的全部面积都位于红移区, 如果有更为靠近耀 斑发生时的 Doppler 图,情况可能会更好一些. 剩下的 19 个亮点或亮带耀前没有 Doppler 图, 只在耀斑开始之后的 $5 \mathrm{~min}$ 之内有 $\mathrm{H}_{\beta}$ Doppler 图, 这些亮点或亮带全部位于红移区. 我 们还查看了一些其他区的历史资料,发现类似情况,看来这是一个新的事实.

（2）耀斑在 $\mathrm{H}_{\beta}$ Doppler 图上靠近速度反变线的程度明显地超过篚近纵场反变线的程 度. 如该区 138 个亮点和亮带中, 有 47 个与纵场反变线的距离超过 10", 而在 Doppler 图 上, 只有 7 个亮点与速度反变线距离约有 $5^{\prime \prime}$, 而其他 131 个均小于 $5^{\prime \prime}$.

（3）耀斑的边缘形状既对应于纵场反变线形状,又对应于 Doppler 反变线形状, 但主要 对应于 Doppler 速度反变线形状. 在一些情况下, 耀斑的形状几乎完全对应于 Doppler 速 度反变线形状.

（4）相似耀斑之间的差别主要对应于耀斑前 Doppler 速度反变线红移一侧形状的差别。

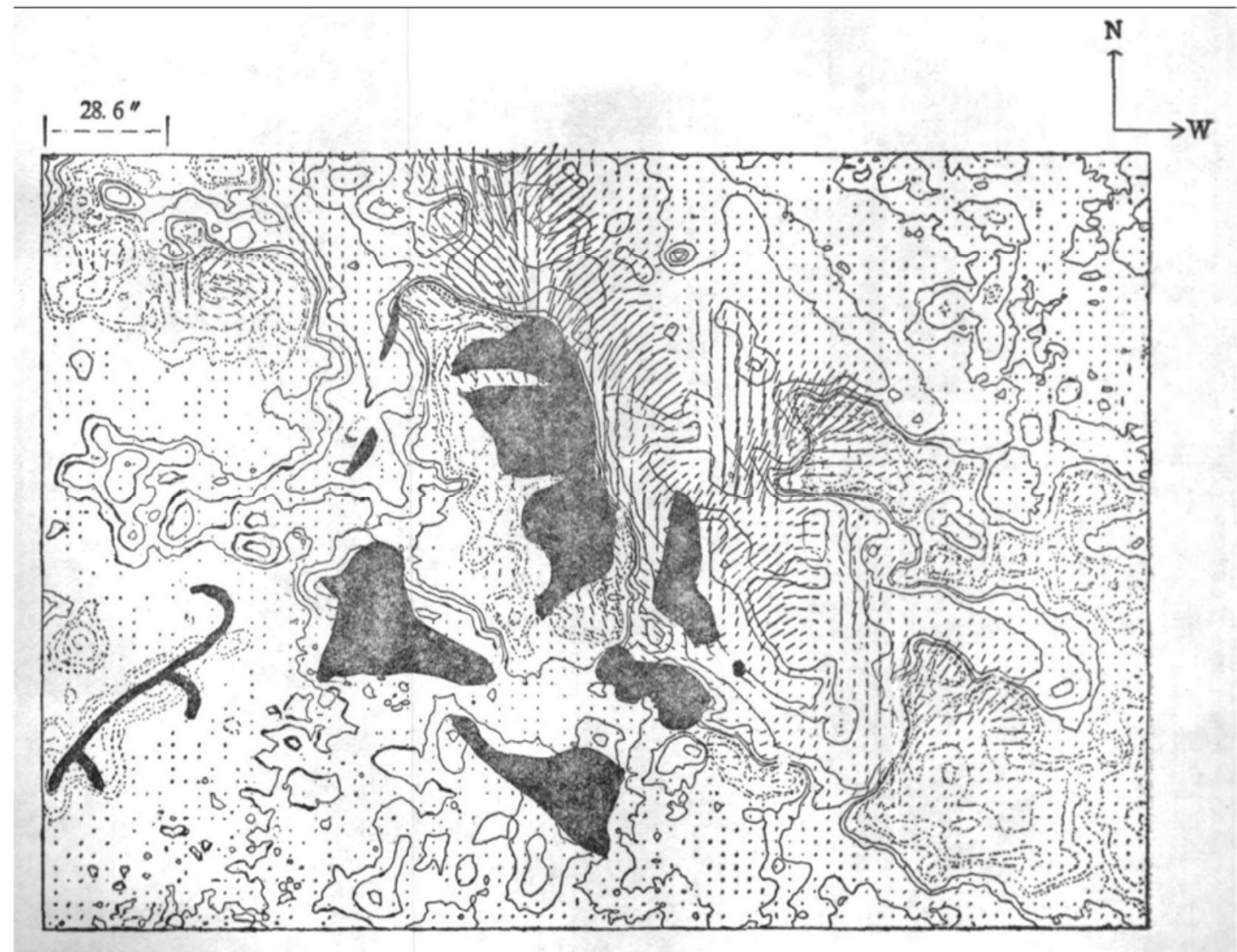

图 $2 \mathrm{H}_{6}$ Doppler 速度图 0250UT 1989 年3 月 13 日 0309 现 
(5) 许多解出现在 $\mathrm{H}_{B}$ Doppler 速度反变线扭曲成 “ $\mathrm{S}$ " 形或圆形的区域, 在 “ $\mathrm{S}$ ” 的海 湾两端具有相反的流向, 即存在速度交叉的情况, 耀斑发生于红移区. 耀斑发生时的类似情况 曾被指出过 ${ }^{[2]}$.

（6）在磁挤压过程中, 如果磁反变线两侧都属 Doppler 红移结构, 则这种地方出现耀斑 的可能性增大.

（7）如果磁反变线两侧具有红移,并有强磁学切存在,则双带耀斑出现的可能性增大.

（8）如果在一个发达的“ $S^{n}$ 形磁反变线结构中发现新浮出磁通量, 并具有 Doppler 红移 特征, 大耀斑可能性增大.

(9) Doppler 速度图上红移区变化较快的区, 具有较多的耀斑可能.

(10) 一些耀玟出现在远离磁反变线的磁同极区, 但存在于复杂的 Doppler 速度结构之 中,这表明由相对运动引起的磁紧张可能引起耀斑.

作为实例，3 月 13 日大耀琣的矢量磁图及 Doppier 图示于图 1 和图 2.

有关 Doppler 速度场的演化与耀琣的关系的电视录像带正在制作中, 有关细节将另文报 洋.

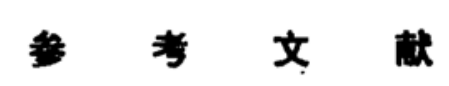

[1] Ai, G. et al., Chinese Science Bulletin, 33(1988), 13: 1107.

[2] Li, J. et al., Acta Astrophysica Sinica, 8(1908), 4: 301. 